\section{Asian elephant threatened}

SIR - Pagel and Mace ${ }^{1}$ present a strong argument in favour of the current ban on trade in elephant products. The halving of the African elephant population in the past eight years is justly a cause for concern. But we wish to draw attention to a generally overlooked aspect of elephant conservation - that there are two species of elephants, and that the CITES ban has minimal benefits in the conservation of the Asian species, Elephas maximus L.

The Asian elephant is much rarer than its African cousin. Current estimates are imprecise, but put the number of wild Asian elephants at $34,000-56,000$ with a further 16,000 in captivity ${ }^{2}$. Even optimistic figures indicate that there are only one tenth as many Asian as African elephants $^{2,3}$. Asian elephant numbers may not have undergone a dramatic decline in recent years, but the species faces much more intractable conservation problems.

Elephant poaching may be a relatively minor problem in Asia today and, because some males and all females lack tusks $^{5}$, poaching cannot be the terminal threat it is in Africa. Much more important for the Asian elephant are habitat loss and fragmentation as a result of escalating human population, which in turn leads to increasing conflict between man and elephant. In India, for example, which may contain half of all wild Asian elephants, the human population increased from 236 to 790 million in the period 1901-884. This increase places intense pressure on undeveloped areas. Only one-third of Asian elephant habitat is in protected areas ${ }^{4}$.

Erosion of habitat forces elephants into agricultural areas, where they destroy crops and inevitably cause human fatalities: $150-200$ a year in India ${ }^{4}$. Most remaining populations are already small. Fragmentation of habitat leads to fragmentation of elephant populations. In Thailand, 29 protected areas hold 1,3001,700 elephants, but only 13 of these areas hold more than 25 individuals ${ }^{4}$. Many Asian elephant populations in the longer term may not be viable ${ }^{2,6}$. It does not help that many of the larger elephant populations are located in politically unstable areas - for example the 8,500 11,000 elephants in northeast India ${ }^{2}$. The destruction wrought in Manas National Park, Assam, by Bodo secessionists shows how vulnerable even protected areas are to political unrest. In the Vietnam war, US forces bombed elephants because the Viet-Cong were using them as transport ${ }^{4}$.

None of the problems faced by the Asian elephant can be alleviated overnight as poaching has been in Africa. Neither has much effort been expended by the international community in finding ways in which human and elephant populations can successfully co-exist (although the individual countries involved are trying to tackle these problems). This state of affairs must be rectified, because the continued success of the CITES ban, coupled with human population growth, will result in the Asian situation being repeated in Africa in the near future. It will be in the long-term interests of both elephant species to find solutions to the Asian elephant's problems now.

SHANTHINI DAWSON

Asian Elephant Specialist Group,

49 Model House Street,

Bangalore 560004, India

TIM M. BLACKBURN

Centre of Population Biology,

Imperial College at Silwood Park,

Ascot, Berkshire SL5 7PY, UK

1. Pagel, M. D. \& Mace, R. Nature 351, 265-266 (1991). 2. Santiapillai, C. \& Jackson, P. The Asian Elephant: an Action Plan for its Conservation (IUCN, Gland, 1990).

3. Cherry, M. I. Nature 351, 7 (1991)

4. Sukumar, R. The Asian Elephant: Ecology and Management (Cambridge University Press, 1989)

5. Shoshani, J. \& Eisenberg, J. F. Elephas maximus (Mammalian Species 182, American Society of Mamma logists, 1982).

6. Soule, M. E. Viable Populations for Conservation (Cambridge University Press, 1987).

\section{Origin of bacterial adaptation}

SIR - Harry Rubin's letter ${ }^{1}$ is welcome in pointing to the stimulating contribution of the late Sir Cyril Hinshelwood to debates in the 1940s and 1950s on the origin of bacterial adaptation. Rubin does not, however, make clear why this contribution was less helpful than it might have been.

As Rubin correctly says, Hinshelwood did not argue that adaptation in bacteria could never arise by mutation, and indeed sometimes accepted this as an explanation ${ }^{2}$. He was, however, more concerned with phenomena, in particular the 'training' of bacterial cultures to increasingly higher levels of antibacterial agents, where he considered this explanation unlikely. His reasons for questioning it in such contexts remain cogent, and it is true that no complete explanation of the observations is available even now, although it could be argued that he remained unwilling to accept fully the implications of the likelihood of polygenic drug resistance even when evidence in accord with this was obtained in his own laboratory ${ }^{3}$.

However, the features alluded to by Rubin, namely "the speed of change, the large fraction of the population involved, the finely graded nature of the response, the lack of precise specificity and the reversibility of the altered state", do not have to possess an origin in self-adjusting changes in flow through different reaction networks, as Hinshelwood supposed. One is inclined nowadays to suspect the involvement of stress responses mediated by specific control mechanisms, such as the heat-shock system.

We are perhaps used to thinking of such systems, especially in bacteria, as solely providing quick but rapidly reversible responses. But there is no reason why other sorts of kinetic behaviour should not occur, as pointed out long ago by Monod and $\mathrm{Jacob}^{4}$ (see also the reference to an earlier model by Delbrück on page 398 of this citation). It may be that Hinshelwood's recognition of this led him never to dispute the lac paradigm directly (as far as I know). (That we usually do not consider the potentially flexible kinetic behaviour of even moderately complex control systems mediated by specific molecular mechanisms is probably due to the disinclination of those working in this area, such as myself, to do much mathematical modelling.) There seems no reason in principle why such responses might not be involved in the extremely interesting phenomena described by Rubin ${ }^{5}$ as well as in the other cases he refers to in his letter.

In fairness to Hinshelwood, it should be pointed out that he was remarkably tolerant of work in his own laboratory, such as my own modest effort ${ }^{6}$, that seemed to go against his own views.

SIMON BAUMBERG

Department of Genetics,

University of Leeds,

Leeds LS2 9JT, UK

1. Rubin, H. Nature 351, 600 (1991).

2. Drabble, W. T. \& Hinshelwood, C. N. Proc. R. Soc. B 154 449-457 (1961)

3. Bartlett, G. W. \& Hinshelwood, C. N. Proc. R. Soc. B 150 318-326 (1959)

. Monod, J. \& Jacob, F. Cold Spring Harb. Symp. quant Biol. 26, 389-401 (1961).

5ubin, A. L., Yao, A. \& Rubin, H. Proc. natn. Acad. Sci. U.S.A. 87, 482-486 (1990)

6. Baumberg, S. J. gen. Microbiol. 43, 357-367 (1966).

\section{Grant to HUGO}

SIR - In two recent articles on the Human Genome Project (Nature 352, 3 \& $11 ; 1991)$ you stated that the Soviet government was the only government or public grant-making agency to have funded HUGO (the Human Genome Organisation). This is not true and I would be grateful if you would set the record straight. The Australian government has already made a grant of $\$ \mathrm{~A} 50,000$ to HUGO.

WALTER BODMER (President)

HUGO EUROPE

5th Floor, 179 Great Portland Street. London W1N 5TB, UK 